\title{
The Implementation of Computerized Physician Order Entry in the Intensive Care Unit
}

\author{
Huawen Zhang ${ }^{1}$
}

${ }^{1}$ Department of Pharmacy, Qingdao University, China

\begin{abstract}
Computerized physician order entry (CPOE) has been known as a process of physician orders in an electronic way instead of the traditional paper-based system. CPOE has been included as one of core objectives in the term 'Meaningful Use' by Centers for Medicare and Medicaid Services. The U.S. Department of Health and Human Services Office of Inspector General reported 180,000 deaths in the United States in 2008 due to medication errors. The Institute of Medicine reported about 450,000 preventable adverse drug effects which costed additional $\$ 3.5$ billion. On average, 1.7 medication errors per day and $74.5 \%$ errors in parenteral drugs administration were reported in the intensive care unit (ICU). The purpose of this research was to examine the benefits, barriers and risks of CPOE adoption in different ICUs. The methodology for this study was a literature review. Research was conducted by collecting scholarly online database and government websites. On one hand, CPOE could provide patient's health record regardless of time and place, alerts in drug interactions, and suggest in clinical decisions in ICUs. CPOE could also reduce medication errors and adverse drug events significantly. On the other hand, CPOE could provide better solutions if it would be used with real-time conversation and as per workflow of ICUs. In addition, user satisfaction and sufficient training, were important factors in implementing CPOE with more successful and desired outcomes.
\end{abstract}

Keywords: CPOE, Medication Errors, Adverse Drug Events, Intensive Care Units

\section{Introduction:}

Computerized physician order entry (CPOE) has been introduced as a process of medical orders in an electronic way to replace the traditional paper-based lengthy system which with many clinical errors. CPOE has improved coordination in clinical processes effectively in reducing length of stay and related medication errors (Romanow, Rai, Keil, \& Luxenberg, 2017). On February 17, 2009, with the aim of providing better and more secure health care to overall population, the Health Information Technology for Economic and Clinical Health Act $(\mathrm{HITECH})$ was introduced under the American Recovery and Reinvestment Act (ARRA) (Recovery Act, 2009). The primary target of introducing Health Information Technology (HIT) system with its tools such as electronic health record (EHR) or electronic medical record (EMR) software, was to improve quality of patient care and to provide affordable health care.

For health care providers, "Meaningful Use" has been used by the Centers for Medicare and Medicaid Services (CMS) with 15 core objective measures for registering and getting incentives under Certified Electronic Health Record Technology program (Centers for Medicare \& Medicaid Services, 2010). Meaningful use has three stages, and CPOE has been one part of all stages. Most health care providers have adopted CPOE not only for higher accessibility to patient data, but also to decrease prescription errors and adverse drug events (ADEs).

The U.S. Department of Health and Human Services Office of Inspector General reported 180,000 deaths which might have been caused by medication errors in 2008 (Makary, \& Daniel, 2016). The Institute of Medicine (IOM) has reported that about 450,000 preventable ADEs costed additional $\$ 3.5$ billion in the U.S. every year (Aspden, Wolcott, \& Bootman, 2007).

There was more ADEs happening in the ICU than any other department of hospitals and about $74.5 \%$ errors were reported in parenteral drugs administration in different ICUs around the world with those old paper-based systems (Valentin et al., 2009). It has been observed that an average of 1.7 errors occurred per day in the ICU in the globe, and $78 \%$ of those errors were caused by medication orders (Camiré, Moyen, \& Stelfox, 2009). However, CPOE has basically changed the old medication order process and help to reduce overuse, underuse and misuse of health care services.

This article is published under the terms of the Creative Commons Attribution License 4.0 Author(s) retain the copyright of this article. Publication rights with Alkhaer Publications. Published at: http://www.ijsciences.com/pub/issue/2021-01/

DOI: 10.18483/ijSci.2432; Online ISSN: 2305-3925; Print ISSN: 2410-4477 
According to the survey from Joint Commission in 2005, two third of root causes of sentinel events were related to interruptive communication (Joint commission, 2008). Therefore, effective communication with CPOE has become an essential part of patient safety within health care organizations.

Only $15 \%$ of hospitals adopted CPOE until 2010; however, the application of CPOE has been increasing in recent few years (Hoonakker, Carayon, $\&$ Walker, 2010). Another study has reported that about $62 \%$ large, $47 \%$ medium, and $38 \%$ small hospitals have adopted CPOE for medications in 2012 (Nuckols et al., 2014). In addition, the implication of Meaningful Use has been gone up to $95 \%$ of Medicare eligible hospitals until 2015 (Romanow, Rai, Keil, \& Luxenberg, 2017).

The purpose of this study was to assess the benefits, barriers and risks of CPOE adoption in different ICUs and to determine user satisfaction of its provider.

\section{Methodology:}

The primary hypothesis of this study was to assess if the implementation of CPOE will reduce medication errors and ADEs in the ICU. The secondary hypothesis was to examine if CPOE adoption will increase patient safety in ICUs.

The methodology for the examination of the benefits of, barriers to and risks of CPOE adoption in ICUs followed the basic principles of a systematic review. The study was conducted in three stages: (1) identifying the literature and collecting the data, (2) analyzing and evaluating the literature found, and (3) categorizing the literature.

\section{Literature Identification and Collection}

The Academic Search Premier, PubMed, ProQuest, ScienceDirect, and Google Scholar electronic databases were searched for the terms "CPOE" or "Computerized Physician Order Entry" or "Electronic Prescribing" and "Medical Errors" or "Adverse Drug Events" and "Adoption" or "Implementation". Reputable websites such as Federal Register and CMS were also used. Citations and abstracts were also assessed to identify relevant articles.

\section{Literature Analysis}

Literature was selected based on benefits of, barriers to and risks of CPOE adoption in the ICU. Only articles published from 2005 to 2017 were chosen. The search was restricted to sources attainable as full texts and written in English. A total of 19 references and citations were utilized for this study.

\section{Literature Categorization}

Abstracts of the articles were reviewed first to determine if they were relevant to this study. After that those academic articles and studies selected from the abstract reviews were analyzed, and the findings were categorized under the subheadings of benefits of, barriers to and risk of CPOE adoption in the ICU.

\section{Results:}

\section{Benefits of CPOE in the ICU}

The implementation of CPOE has been beneficial in providing fast clinical processes with less required participants in the work place and avoiding various types of clinical errors due to miscommunication and inefficient workflow (Hoonakker et al., 2013). A Study performed in a pediatric ICU on 26 physicians with 234 drip orders showed that CPOE were not only efficient in taking less time (5.5 minutes \pm 2 minutes) as compared to the handwritten method (26 minutes \pm 8 minutes), but also in reducing errors from 170 of 234 drip orders (73\%) to 10 of 234 drip orders (4.3\%) (Vaidya et al., 2006). It was also reported that time efficiency with CPOE was 5 times faster than paper-based system, and prescription errors have significantly dropped about $80 \%$ after CPOE adoption (Vaidya et al., 2006).

A study which has been performed in the ICU found that two third of prescription errors were associated with verbal orders; however, the adoption of CPOE provided beneficial results (Cho, Park, Choi, Hwang, $\&$ Bates, 2014). A questionnaire performed in 2007 on physicians, nurses and other users at a 400-bed rural hospital in four ICUS with response rate of $47 \%$, and users were satisfied in with its reliability, patient safety, and effective communication (Hoonakker et al., 2013).

CPOE with clinical decision support system (CDSS) has been an important tool in reducing ADEs by providing drug allergy information and interaction alerts (Wolfstadt et al., 2008). In 2004, Colpaert et al performed a trial study in a 22-bed ICU with 1,286 CPOE based and 1,224 paper-based medication and fluid prescriptions, and the results showed that a reduction in MPEs and ADEs from $27 \%$ and $0.98 \%$ of paper-based orders to $3.4 \%$ and $0.16 \%$ of CPOE orders (Table 1) (Colpaert et al, 2006). 


\begin{tabular}{|l|l|l|}
\hline & CPOE Orders & Paper-Based Orders \\
\hline Total Prescriptions & 1,286 & 1,224 \\
\hline Total MPEs & 44 & 331 \\
\hline$\%$ MPEs & 3.4 & 27.0 \\
\hline Total ADEs & 2 & 12 \\
\hline$\%$ ADEs & 0.16 & 0.98 \\
\hline
\end{tabular}

Table 1. MPEs and ADEs analysis in CPOE orders and Paper-based orders

Clinical errors have been identified at every stage in the process of ordering to administering medications; however, CPOE with barcode technology has been found effective not only in reducing incidences of MPEs by about $50 \%$, but also in helping health care professionals check drug interactions, dose errors and different ADEs in the ICU (Fumis et al., 2014). $\mathrm{CPOE}$ has played a significant role in reducing medication errors of $55 \%$ to $80 \%$ by decreasing the occurrence of illegible orders, inappropriate doses and incomplete orders (Colpaert et al., 2006). In addition, CPOE adoption were beneficial for patients in lowering cost by decreasing ADEs and reducing the duration of ICU stay. Other beneficial outcomes after adopting CPOE in the ICU including all relevant data could be acquired at a time, such as allergies, drug-drug interactions and contraindications, and actions could be taken immediately.

\section{Barriers to $C P O E$ in the ICU}

The major barrier of adopting CPOE was lacking experience in using CPOE due to insufficient training period for its users (Cho, et al., 2014). A study was conducted for user satisfaction in a 30-bed surgical ICU located in Brazil, which revealed the average scores were about 5 among overall users and 6.50 among ICU staff (Figure 1). (Fumis et al., 2014). MPEs were still reported even after the adoption of CPOE as a result of the resistance and fear of health care professionals, especially for older age health care professionals who lacked computer literacy (Fumis et al., 2014). A study has been performed by Maslove et al found that in 2002 the cost of adopting CPOE for small hospital (200 beds) was $\$ 500,000$ and \$15 million for large hospital (1000 beds), including licensing fees, hardware and software maintenance (Maslove, Rizk, \& Lowe, 2011). Therefore, cost has been another important barrier for the adoption of CPOE especially for small-sized organizations.

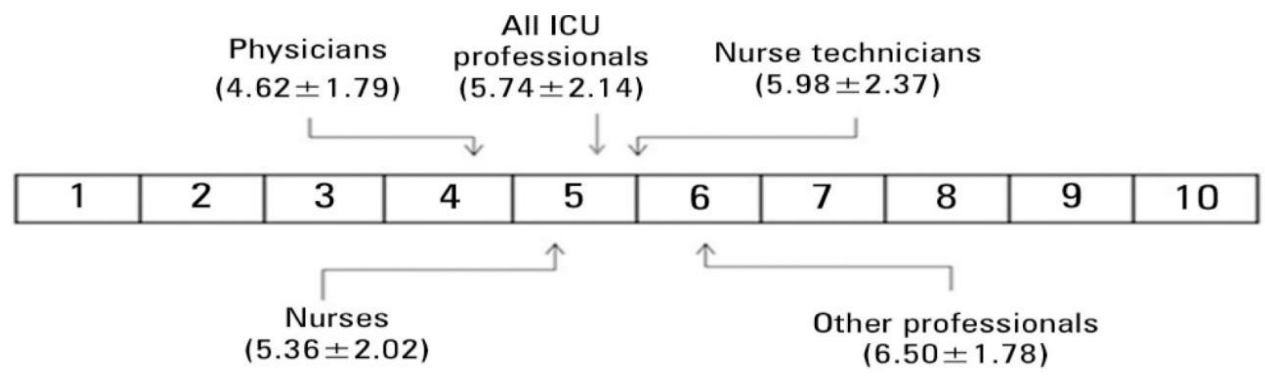

Figure 1. Global satisfaction with the CPOE. The figure presents the score of each individual group and for all ICU professionals computed together. $1=$ low satisfaction, $10=$ high satisfaction.

\section{Risks of CPOE in the ICU}

Shulman et al found two non-intercepted errors with CPOE have caused an increased length of stay in the ICU, and three intercepted errors with CPOE have caused permanent harm to patients or death (Shulman, Singer, Goldstone, \& Bellingan, 2005). Hundt et al found that there were some vulnerabilities with CPOE implementation, such as automatic discontinuation of orders, and hard to distinguish "STAT" (Latin term widely used in medicine practice meaning "immediately") versus "NOW" orders, which caused issues in patient safety, quality of care, cognitive burden for users, and worker inconvenience or distress (Hundt et al., 2013).

\section{Discussion:}

This study contributed to my knowledge of the implementation of CPOE in the ICU. My study concluded that the overall use of CPOE in the ICU can vary significantly, and it has become an essential tool for today's health care system. CPOE could provide patient health record and alerts in drug interactions regardless of time and place. Physicians could also provide their expert suggestions anytime even if they were not present in the workplace. In addition, CPOE has been efficient in time saving and reduction of different clinical errors, and then contributed to patient safety and quality of health care. ADEs used to be known as a factor of expensive health care by increasing length of stay for patients. The results of my study by reviewing literatures and 
case studies revealed that the adoption of CPOE has been beneficial in terms of reducing MPEs and ADEs significantly, and by reducing ADEs, CPOE has markedly become an efficient tool in health care delivery to cut down the cost of health care in the US.

Although CPOE has been a beneficial and effective system in health care delivery, this study found that this technology should be improved for better outcome in terms of patient care. One of the literatures used in this study revealed that nurses intercepted some prescriptions errors even with CPOE and corrected them before it reached to patients. CPOE could provide better solutions if it would be used with real-time conversation and as per workflow of ICUs. Physicians did not have access to the system and orders made at another place while visiting patients; therefore, this gap caused interruption in workflow of the ICU and confusion in following orders for other staff, and then resulted in potential harm to patients. If CPOE system could be available at patients' bed on real time, it could be more efficient and beneficial. In addition, physicians and nursing staff decision would be improved if it could be applied with CDSS, and then resulted in less clinical errors with desired outcomes. On the other hand, medical terminology and broad drug selection options should be considered by software companies to make more efficient and user-friendly CPOE system.

This study indicated that user satisfaction is one of the factors where further research should be done. Users who were given insufficient training and technical support were less satisfied than those who received sufficient training. Old-age users were also found not satisfied with CPOE system because they were not comfortable with new technologies and usually spent their time with handwritten ordering system. Sufficient training to its users and 24-hour technical support would enhance this technology in terms of patient safety. In addition, cost of CPOE implementation, software and hardware maintenance have become the barriers to adopt CPOE system, but federal government or nonprofit charitable organizations could assist small health care providers in the adoption of CPOE.

\section{Conclusion:}

The implementation of CPOE in the ICU has been beneficial and essential for population of the US in term of patient safety and quality of care. Factors such as CDSS, and real-time use at bedside could provide better results. Physicians and other users would continue to work with this technology, and remaining problems could be reduced in efficient way.

\section{References:}

1. Aspden, P., Wolcott, J. A., Bootman, J. L. \& Cronenwett, L. R. (2007). Committee on identifying and preventing medication errors: Preventing medication errors. Washington, DC: National Academies Press.

2. Camiré, E., Moyen, E., \& Stelfox, H. T. (2009). Medication errors in critical care: Risk factors, prevention and disclosure. Canadian Medical Association Journal, 180(9), 936-943. https://doi.org/10.1503/cmaj.080869.

3. Centers for Medicare \& Medicaid Services (CMS), HHS (2010). Medicare and Medicaid programs; electronic health record incentive program. Final rule. Federal Register, 75(144), 44313-588. PMID: 20677415.

4. Cho, I., Park, H., Choi, Y. J., Hwang, M. H., \& Bates, D. W. (2014). Understanding the nature of medication errors in an ICU with a computerized physician order entry system. PLoS One, 9(12),

e114243.

https://doi.org/10.1371/journal.pone.0114243.

5. Colpaert, K., Claus, B., Somers, A., Vandewoude, K., Robays, H., \& Decruyenaere, J. (2006). Impact of computerized physician order entry on medication prescription errors in the intensive care unit: A controlled cross-sectional trial. Critical Care, 10(1), R21. https://doi.org/10.1186/cc3983.

6. Fumis, R. R. L., Costa, E. L. V., Martins, P. S., Pizzo, V., Souza, I. A., \& Schettino, G. D. P. P. (2014). Is the ICU staff satisfied with the computerized physician order entry? A cross-sectional survey study. Revista Brasileira de Terapia Intensiva, 26(1), 1-6. https://doi.org/10.5935/0103507x.20140001.

7. Hoonakker, P. L., Carayon, P., Brown, R. L., Cartmill, R. S., Wetterneck, T. B., \& Walker, J. M. (2013). Changes in enduser satisfaction with Computerized Provider Order Entry over time among nurses and providers in intensive care units. Journal of the American Medical Informatics Association, 20(2), 252-259. https://doi.org/10.1136/amiajnl2012-001114.

8. Hoonakker, P. L., Carayon, P., \& Walker, J. M. (2010) Measurement of CPOE end-user satisfaction among ICU physicians and nurses. Applied Clinical Informatics, 1(3), 268-285. https://doi.org/10.4338/aci-2010-03-ra-0020.

9. Hundt, A. S., Adams, J. A., Schmid, J. A., Musser, L. M., Walker, J. M., Wetterneck, T. B., ... \& Carayon, P. (2013). Conducting an efficient proactive risk assessment prior to CPOE implementation in an intensive care unit. International Journal of Medical Informatics, 82(1), 25-38. https://doi.org/10.1016/j.ijmedinf.2012.04.005.

10. Joint Commission on Accreditation of Healthcare Organizations. (2008). Safely implementing health information and converging technologies. Sentinel Event Alert, 42, 1-4. PMID: 19108351.

11. Makary, M. A., \& Daniel, M. (2016). Medical error-the third leading cause of death in the US. The BMJ,353, i2139. https://doi.org/10.1136/bmj.i2139.

12. Maslove, D. M., Rizk, N., \& Lowe, H. J. (2011). Computerized physician order entry in the critical care environment: A review of current literature. Journal of Intensive Care Medicine, 26(3), 165-171. https://doi.org/10.1177/0885066610387984.

13. Nuckols, T. K., Smith-Spangler, C., Morton, S. C., Asch, S. M., Patel, V. M., Anderson, L. J., ... \& Shekelle, P. G. (2014). The effectiveness of computerized order entry at reducing preventable adverse drug events and medication errors in hospital settings: A systematic review and metaanalysis. Systematic Reviews, 3(1), 56 https://doi.org/10.1186/2046-4053-3-56.

14. Recovery Act. (2009). American Recovery and Reinvestment Act of 2009. Public Law, 111(5), 5-30.

15. Romanow, D., Rai, A., Keil, M., \& Luxenberg, S. (2017). Does extended CPOE use reduce patient length of stay?. International Journal of Medical Informatics, 97, 128138. https://doi.org/10.1016/j.ijmedinf.2016.09.012. 
16. Shulman, R., Singer, M., Goldstone, J., \& Bellingan, G. (2005). Medication errors: A prospective cohort study of hand-written and computerised physician order entry in the intensive care unit. Critical Care, 9(5), R516. https://doi.org/10.1186/cc3793.

17. Vaidya, V., Sowan, A. K., Mills, M. E., Soeken, K., Gaffoor, M., \& Hilmas, E. (2006). Evaluating the safety and efficiency of a CPOE system for continuous medication infusions in a pediatric ICU. AMIA Annual Symposium Proceedings, 2006, 1128. PMID: 17238747; PMCID: PMC1839548.
18. Valentin, A., Capuzzo, M., Guidet, B., Moreno, R., Metnitz, B., Bauer, P., \& Metnitz, P. (2009). Errors in administration of parenteral drugs in intensive care units: Multinational prospective study. The $\quad B M J, 338, \quad \mathrm{~b} 814$ https://doi.org/10.1136/bmj.b814

19. Wolfstadt, J. I., Gurwitz, J. H., Field, T. S., Lee, M., Kalkar, S., Wu, W., \& Rochon, P. A. (2008). The effect of computerized physician order entry with clinical decision support on the rates of adverse drug events: A systematic review. Journal of General Internal Medicine, 23(4), 451458 https://doi.org/10.1007/s11606-008-0504-5. 